\title{
Mechanisms of Fracture in Neutron-Irradiated 15Ch2MFA Steel
}

\section{Š. Válek, ${ }^{1, a}$ P. Haušild, ${ }^{1, b}$ and M. Kytka ${ }^{2, e}$}

${ }^{1}$ Czech Technical University in Prague, Faculty of Nuclear Sciences and Physical Engineering, Department of Materials, Prague, Czech Republic

${ }^{2}$ Řež Nuclear Research Institute, Řež, Czech Republic

a Stepan.Valek@fjfi.cvut.cz, ${ }^{b}$ Petr.Hausild@fjfi.cvut.cz, ${ }^{\mathrm{c}}$ kyt@ujv.cz

The influence of irradiation on fracture properties of 15Ch2MFA pressure vessel steel is studied. The distribution of inclusions and carbides is characterized. The quantitative fractography of broken Charpy specimens is carried out. The correlation of crack initiation energy and the area of ductile fracture adjacent to the notch is identified. It is shown that most of the absorbed energy belongs to the stage preceding the cleavage crack initiation. From the fracture surface of Charpy specimens the distribution of ductile dimples is investigated. The relationship between the distributions of ductile dimples and second phase particles is discussed.

Keywords: quantitative fractography, instrumented Charpy test, fracture energy, ductile-to-brittle transition temperature.

Introduction. Neutron irradiation has the key influence on the ductile-to-brittle transition temperature (DBTT) shift in 15Ch2MFA pressure vessel steel. In the DBTT range, the prediction of fracture is complicated, since two fracture micromechanisms are in competition. The final (brittle) fracture is frequently preceded by stable ductile tearing. The ductile crack growth preceding the unstable fracture changes the stress-strain field ahead of the crack tip (stress, strain, and constraint). We study the relation between the unstable crack initiation and ductile crack extension in irradiated steel by means of quantitative fractographic analysis.

Experimental Results. Tempered bainitic steel 15Ch2MFA used for manufacturing of pressure vessel of VVER440 reactor was studied $[1,2]$. The forged plate of $190 \mathrm{~mm}$ thickness was subjected to the thermal treatment of normalizing at $1010^{\circ} \mathrm{C} / 12 \mathrm{~h}$ followed by cooling in air, and tempering at $730^{\circ} \mathrm{C} / 14 \mathrm{~h}$ followed by furnace cooling. The chemical composition is given in Table 1 . The microstructure is the same for all three directions of forging and the mean bainitic packet size is around $30 \mu \mathrm{m}$.

$\mathrm{T}$ a b 1 e 1

Chemical Composition of 15Ch2MFA Steel (wt.\%)

\begin{tabular}{|c|c|c|c|c|c|c|c|c|c|c|c|}
\hline $\mathrm{C}$ & $\mathrm{Mn}$ & $\mathrm{Si}$ & $\mathrm{P}$ & $\mathrm{S}$ & $\mathrm{Cu}$ & $\mathrm{Cr}$ & $\mathrm{Ni}$ & $\mathrm{Mo}$ & $\mathrm{Co}$ & $\mathrm{V}$ & $\mathrm{As}$ \\
\hline 0.18 & 0.50 & 0.31 & 0.014 & 0.016 & 0.10 & 2.80 & 0.07 & 0.65 & 0.009 & 0.009 & 0.009 \\
\hline
\end{tabular}

Using Scanning Electron Microscope (SEM) Jeol JSM 5510 LV, the microanalysis of second phase particles (inclusions) was carried out. X-ray analysis revealed the MnS inclusions. The distribution of these inclusions was obtained using image analysis.

The image analysis was performed for different magnifications using images obtained from both electron and optical microscopy. For the electron microscopy, the backscattered electron signal (mode COMPO) was used. The total number of particles found was 1882 and the investigated area was $28.8 \mathrm{~mm}^{2}$. Good agreement was found in distribution of sizes of particles for both electron and optical microscopy and for different magnifications. 
Using SEM in the secondary electron mode, polished and etched specimens were investigated in order to characterize the distribution of fine carbides in bainitic microstructure. For the image analysis the magnification $\times 10,000$ was used. Within the area of $1228 \mu \mathrm{m}^{2}$ there were found 1342 particles. It can be concluded that there are two different populations of particles: MnS inclusions and carbides, each with its own independent distribution of particle sizes.

The standard Charpy V-notch (CVN) specimens were taken at a depth position at one quarter of the plate thickness from the surface ( $1 / 4 t$ position) in the $\mathrm{T}$ (long transverse) and $\mathrm{T}-\mathrm{S}$ (long transverse-short transverse) orientations. The specimens were enclosed and neutron-irradiated in the same capsules as standard surveillance specimens. The chains contained the set of activation monitors (including fast as well as thermal neutrons) and also fission monitors. Each capsule contained two rings of copper wire to evaluate the azimuthal fluence. The capsules were irradiated in emptied surveillance channels in the VVER 440-type nuclear reactor. The mean irradiation temperature was estimated after evaluation of the melting temperature monitors to $275^{\circ} \mathrm{C}$.

Transition curves of toughness of non-irradiated and neutron irradiated specimens are illustrated in Fig. 1. The DBTT shift after $\Phi=9.7 \cdot 10^{23} \mathrm{n} \cdot \mathrm{m}^{-2}$ is about $50^{\circ} \mathrm{C}$. The instrumented Charpy impact test allowed us to obtain the values of energy, forces, and striker displacement associated with different stages of fracture (Fig. 2). After irradiation, the force at general yield $\left(F_{g y}\right)$ increased, but striker displacement at unstable crack initiation and force at crack arrest $\left(F_{A}\right)$ decreased. The dependence of $F_{A}$ on temperature and irradiation (Fig. 3) also indicates the DBTT shift.

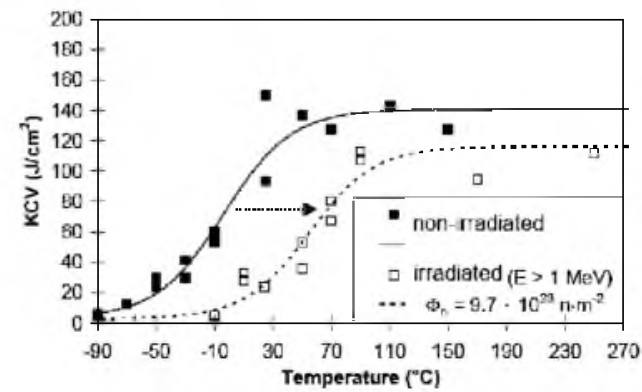

Fig. 1

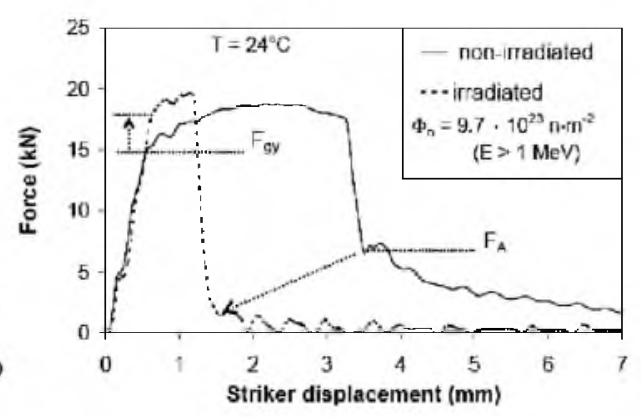

Fig. 2

Fig. 1. Transition curves of neutron irradiated and non-irradiated Charpy impact toughness $K C V$. Fig. 2. Filtered record of signal from instrumented Charpy impact test of neutron irradiated and non-irradiated specimens at room temperature.

The fractographic analysis of Charpy specimens broken in the region of ductile to brittle transition revealed both cleavage facets and ductile dimples on the fracture surfaces. Several types of cleavage initiation were observed. In non-irradiated specimens, cleavage was triggered at lower temperatures on cracked or debonded second phase particles (composed mainly of $\mathrm{MnS}$ ) or initiated directly from the notch root. With increasing temperature, the cleavage crack initiation was preceded by ductile crack growth which forms a dimpled zone situated near the notch. As a consequence, cleavage initiated in the vicinity of the ductile crack tip.

With increasing temperature, small amount of intergranular decohesion occurred and cleavage was in some cases triggered by so produced flaw.

In neutron-irradiated specimens, the amount of intergranular decohesion significantly increased at all temperatures (Fig. 4). As a consequence, at higher temperatures cleavage frequently initiated in areas where the intergranular decohesion 


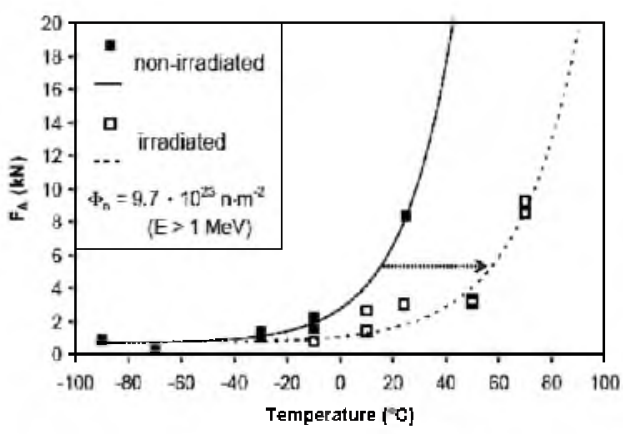

Fig. 3



Fig. 4

Fig. 3. Dependence of $F_{A}$ on temperature and neutron irradiation.

Fig. 4. Intergranular decohesion on the fracture surface of neutron-irradiated Charpy specimen broken at $T=25^{\circ} \mathrm{C}$.

occurred. At low temperatures, cleavage initiated directly from the notch root, probably due to the neutron induced hardening which significantly increased the stresses ahead of the notch root.

In some cases, the cleavage crack arrest and re-initiation (pop-in) occurred in neutron-irradiated specimens.

The changes in fracture mechanisms (change in cleavage triggering mechanism and start of ductile crack growth) occurred in neutron-irradiated specimen at higher temperatures than in non-irradiated specimens as expected from the DBTT shift obtained from Charpy tests (see Fig. 1).

For quantitative fractographic analysis, the methodology developed in [3] was adopted. The areas of different type of fracture in both irradiated and non-irradiated specimens were measured from the images obtained using CCD camera and SEM. The influence of neutron irradiation was observed. The dependence of fraction of ductile fracture on temperature has the same character as the transition curve for energy absorbed during the fracture process.

Correlation between energies obtained from instrumented Charpy tests and areas of fracture surface was investigated. The energy absorbed before unstable crack initiation $\left(W_{i t}\right)$ is closely correlated with ductile area $(A)$ adjacent to the notch root (see Fig. 5). The energy absorbed after crack arrest $\left(K V-W_{i u}\right)$ is correlated with the area of shear lips and final shear fracture. The highest values of energy absorbed are best correlated with the ductile area adjacent to the notch root, even if this area is comparable (in some cases even smaller) with the other ductile areas (shear lips and final shear fracture). It can be concluded that most energy is absorbed during the ductile crack growth from the notch root. The correlations obtained were the same for irradiated and non-irradiated specimens.

The distribution of ductile dimple sizes on fracture surfaces of Charpy specimens was determined using the image analysis. For image analysis, the micrographs obtained at different magnifications ranging from $\times 100$ to $\times 10,000$ were used. The distribution of dimple sizes was obtained for each magnification. Altogether 13,810 dimples were identified. When the overlapping dimple size distributions determined at different magnifications has been plotted all together, the total distribution seems to be continuous in spite of the existence of two different distributions of the second phase particles (inclusions and carbides), participating in ductile rupture. This result is in good agreement with Goods and Brown [4]. It was found that the distribution of dimple sizes does not change with increasing distance form the notch root, which probably means that the mechanism of the ductile crack growth does not change with crack extension. It was also found that irradiation has not influenced the distribution of ductile dimples (Fig. 6), which 


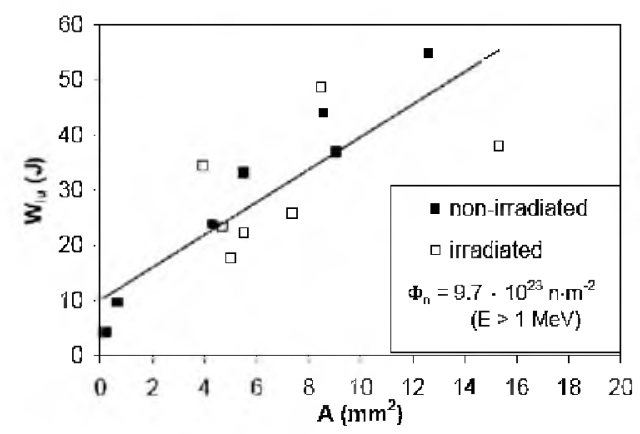

Fig. 5

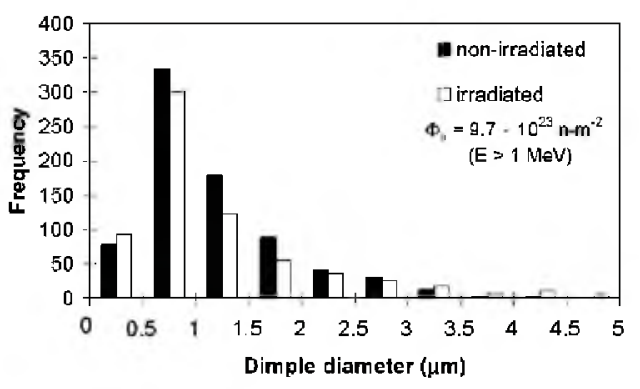

Fig. 6

Fig. 5. The energy absorbed before initiation of unstable crack $W_{i u}$ as a function of area of ductile fracture adjacent to the notch root, $A$.

Fig. 6. Distribution of ductile dimples diameter on fracture surface of irradiated and non-irradiated Charpy specimens.

probably means that the neutron irradiation (at least up to fluence $10^{24} \mathrm{n} \cdot \mathrm{m}^{-2}$ ) does not change the mechanisms of ductile fracture.

Conclusions. The microstructure of $15 \mathrm{Ch} 2 \mathrm{MFA}$ steel was characterized. The 15Ch2MFA steel contained two independent distributions of particles (MnS inclusions and carbides).

The instrumented Charpy tests were performed on non-irradiated and neutronirradiated specimens. The DBTT shift due to irradiation was about $50^{\circ} \mathrm{C}$.

The fractographic analysis of broken Charpy specimens revealed the importance of the ductile crack grow preceding the cleavage initiation. In non-irradiated specimens, cleavage was triggered in cracked second phase particles or initiated in the vicinity of the ductile crack tip. In neutron-irradiated specimens, cleavage initiated in areas where the intergranular decohesion occurred.

The quantitative fractographic analysis showed the correlation of energy absorbed before unstable crack initiation and the area of ductile fracture adjacent to the notch. It was shown that most of the absorbed energy in the transition region belongs to the stage preceding the cleavage crack initiation. The dependencies of the absorbed energy on the ductile area were the same for irradiated and non-irradiated specimens. Moreover, the distribution of ductile dimple sizes did not change with irradiation.

It can be concluded that irradiation has no apparent influence on the mechanisms and kinetics of the ductile crack initiation and growth (at least up to fluence of $10^{24} \mathrm{n} \cdot \mathrm{m}^{-2}$ ).

Acknowledgment. This project has been financially supported by the Ministry of Education. Youth, and Sports of the Czech Republic in the frame of the project No. MSM 6840770020.

1. S. Válek, Physical Mechanism of Brittle Fracture in Low-Alloy Steels, Master Thesis, Czech Technical University in Prague (2006), pp. 1-75.

2. P. Haušild, M. Kytka, M. Karlík, and P. Pešek, "Influence of irradiation on the ductile fracture of a reactor pressure vessel steel," J. Nucl. Mater., 341, No. 2-3, 184-188 (2005).

3. P. Haušild, I. Nedbal, C. Berdin, and C. Prioul, "The influence of ductile tearing on fracture energy in the ductile-to-brittle transition temperature range," in: Materials Science and Engineering (2002), pp. 164-174.

4. S. H. Goods and L. M. Brown, "The nucleation of cavities by plastic deformation," Acta Metall., 27, No. 1, 71-85 (1979). 